\title{
Research Paper: Natural Disasters in the Middle-East and North Africa With a Focus on Iran: 1900 to 2015
}

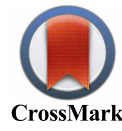

Zohreh Ghomian $^{1}$, Shiva Yousefian ${ }^{1^{*}}$

1. Department of Health in Disasters and Emergencies, School of Health, Safety and Environment, Shahid Beheshti University of Medical Sciences, Tehran, Iran.

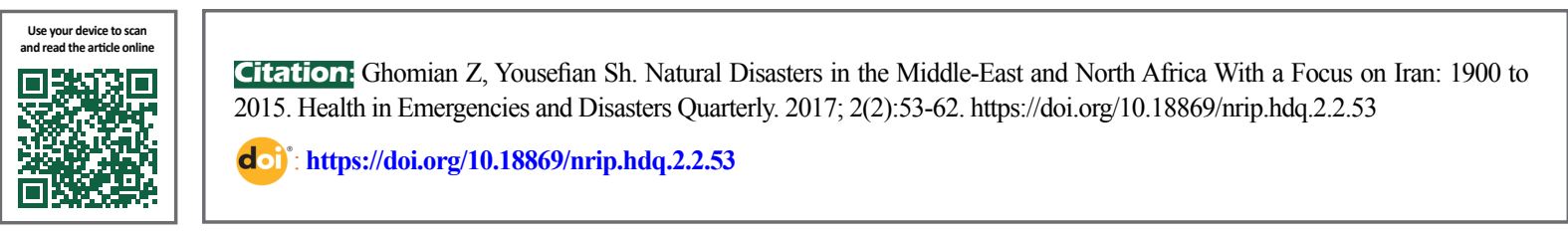

Article info:

Received: 27 Aug. 2016

Accepted: 02 Dec. 2016

\section{Keywords:}

Natural disaster, Middle-East, North Africa, Preparedness, Mitigation

\section{A B S T RACT}

Background: Many types of natural disasters are sudden and calamitous events that create a large socioeconomic burden with significant negative impact on health care, social infrastructure, and the environment; especially in the low and middle income countries; therefore, it is necessary to reduce or control this kind of disasters by understanding the specific risks and negative impacts. Recognition of disaster events helps us to plan effectively, coordinate and invest on disaster risk reduction projects.

Materials and Methods: The current article was a narrative review of the epidemiological data available on natural disasters in MNA countries (Egypt, Jordan, Lebanon, Morocco, Oman, Tunisia, and Yemen) and their trends from 1900 to 2015. The statistical data were obtained from international disaster sources (EM-DAT, DesInventar and Gapminder) and literature reviews of international reports and journals. To find related articles from journals, data bases such as Pubmed, Escopus, Google Scholar, and SID were searched for the following key words: natural disasters, Middle-East, disasters and Middle-East, disasters and North Africa, natural disasters and Middle-East, natural disasters and North Africa, and disaster and trend.

Results: In the last century, more than $80 \%$ of natural disaster events occurred in MNA and concentrated in just 9 countries as Afghanistan, Pakistan, Iran, Sudan, Somalia, Algeria, Morocco, Yemen, and Egypt. Hydrological disasters (flood and landslide) with $63 \%$ had the largest share in 2015 and were more than that of the last century. In 2015 , mortality rate of flood with $11 \%$ and landslides with $32 \%$ had increasing trend compared to last century. In the last 2 years, conversely, damages and victims from flood were about $85 \%$, which were more than those of the last century, but in landslides no change was observed. In 2015, meteorological disasters such as storms and extreme temperatures represented $19 \%$ of the total disaster occurrence that had an increasing trend compared to that of the last century with $12 \%$. Extreme temperatures with $57 \%$ of all deaths and storm with $72 \%$ of total victims had the highest levels among other natural disasters in this period. In the previous years, the total number of death, affected people, and damages of metrological disasters had increasing trend compared to the last century. In addition, in 2015, the frequency of climatological disasters (drought) and geophysical disasters (earthquake) did not change significantly, but the number of affected people, deaths, and damages from drought and earthquakes had a noticeable decrease compared to those of the last century.

Conclusion: The trends of natural disasters frequency from 1900 to 2015 in MNA has increased and effective mitigation and preparedness is necessary, both at individual and governance levels. This issue in the middle income and developing countries in MNA should be considered as a high priority in national planning.

* Corresponding Author: 


\section{Introduction}

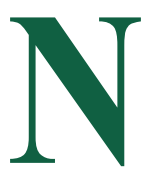

atural disasters are defined by the World Health Organization (WHO) as situations or events caused by nature, which overwhelm local capacity and necessitate requesting a national or international level of external assistance; unforeseen and often sudden events that cause great damage, destruction, and human suffering [1]. Natural disasters that are sudden, calamitous events create a large socioeconomic burden with significant impact on health care costs, social infrastructure, and the environment $[1,2]$.

It is estimated that more than 100000 lives are lost annually as a result of natural disasters [3]. The incidence of morbidity and mortality due to natural disasters varies based on nature, the amplitude of disasters, human, and various environmental factors [4]. Natural disasters create a large socioeconomic burden with significant impact on health care costs, social infrastructure, and the environment. Moreover, most of the natural disasters and disaster-related deaths occur in low-resourced regions (estimated 97\%) with significant proportionate economic loss and long-term negative consequences on human development [2].

Overall, the increasing number of natural disasters and intensified damage they have caused in recent years, and also higher exposure to disasters and the risk of death in low- and middle-income countries necessitate understanding of the specific risks that link negative impacts to disaster events and better coordination, planning and investment on improvement projects. Therefore, coping with changing disaster trends in disaster types, locations and magnitudes can help to manage disasters $[5,6]$. In 2016, 301 natural disasters and 102 affected countries were recorded. The impact of which sums-up of 7628 deaths, 411 million affected people, and US \$ 97 billion economic damages [7]. In this time, Asia was once again the most affected continent by natural disasters, both in terms of death (72\%) and affected people (60\%). Also, Asia with $40 \%$ of the economic losses, after the Americs with $44 \%$ was the 2 nd in this time [7].

Middle-East and North Africa MNA ${ }^{1}$ were hit by 1070 disasters over the 100-year period from 1900 to 2015, with 212832485 affected people in addition to nearly

1. The Middle East and North Africa (MNA) region includes Algeria, Bahrain, Djibouti, Egypt, the Islamic Republic of Iran, Iraq, Jordan, Kuwait, Lebanon, Libya, Morocco, Oman, Qatar, Saudi Arabia, Syrian, Tunisia, the United Arab Emirates, Cyprus, Sudan, Somalia, Afghanistan, Pakistan, and Yemen.
614000 deaths. Economic damages of natural disasters in this region were US $\$ 80$ billion [8]. These facts call for the study of longer time periods to detect a possible trend such as an increasing trend of disaster occurrences among different decades. Sound studies that provide such convincing evidence on ways in which disasters affect individuals, families, and communities are needed. The current study focused on natural disasters and tried to present the result of a survey of disaster trend in 23 countries in MNA designed to overcome this knowledge gap and alert the institutions to the importance of planning for natural disasters. The current study used decade aggregation level to analyze the disaster trends to overcome annual fluctuations. The present study utilized emergency events database (EM-DAT) to obtain the disaster data including data on the effects of disasters in MNA from 1900 to the end of 2015 [9].

\section{Materials and Methods}

The current article was a narrative review of the epidemiological data available on natural disasters in MNA countries and their trends from 1900 to 2015. The statistical data were obtained from international disaster sources (EM-DAT, DesInventar and Gapminder) and literature reviews of international reports and journals. To find the related articles in journals, data bases such as Pubmed, Escopus, Google Scholar, and SID were searched with the following keywords: natural disasters, Middle-East, disasters and Middle-East, disasters and North Africa, natural disasters and Middle-East, natural disasters and s Africa, and disaster and trend.

Inclusion criteria were articles and reports that considered the trends of natural disasters and their side effects in MNA countries from the last century to 2015, and were published in scientific journals or released by prestigious international sites. Exclusion criteria were lack of access to full-text articles, articles published over 10 years ago, and low scientific quality rate. In the initial search for the right combination of keywords, 470 articles were extracted. After reviewing the titles and abstracts, some articles were extracted based on the exclusion criteria. Finally, 35 articles were selected.

The current article studied hazards and exposures, human and economic losses caused due to natural disasters in 23 countries in MNA: Iran, Pakistan, Afghanistan, Algeria, Oman, Yemen, Morocco, Saudi Arabia, Egypt, Sudan, Tunisia, Jordan, Lebanon, Somalia, Iraq, Libya, Syria, Cyprus, Djibouti, Bahrain, Kuwait, Qatar, and United Arab Emirates. 
The study analyzed the data including locations, dates, number of affected people, total number of natural disasters, total death by natural disasters, duration and type of each disaster, and disaster-related economic damage estimates. The study covered the period from 1900 to 2015 and the last decade and last 5 years to observe whether there was a significant change in the locations of disasters and the number of affected people due to those emergencies. Also, the years 2013, 2014, and 2015 were selected to compare the data and, then, all the information was 1st compiled in a folder and, then, processed and analyzed through review. To analyze the data SPSS and Excel software were used and, then, the relevant information was presented in written form, accompanied by figures. As resources get tighter, objective evidence is needed to focus the investments in preparedness and mitigation.

\section{Results}

MNA was hit by 1070 disasters over the 100 -year period, with 212832485 affected people and nearly 614000 deaths. Economic damage of natural disasters in this region was estimated about US $\$ 80$ billion (Table 1).

In the year 2014, natural disasters once again had an important impact on human society. In this year, data indicates that among 23 countries in MNA; in 7 countries disasters occurred and 16 natural disasters were registered. It was $66 \%$ lower than the number of reported disasters in the last century, also in the same range of 2005 to 2015 average. The impact of disasters that happened in these countries was 1128 deaths, 3888094 affected people, and economic damages of US \$ 2413 billion in 2014 (Table 2). Nevertheless, the number of deaths in 2014 was below the average for the last decade (4999 cases), and largely below the 1900 to 2015 average (613634 cases). Economic damages from natural disasters, which was estimated US \$ 2413 billion in 2014, showed a decrease compared to the average of economic damages in the last century.

Among the 7 countries hit by these disasters in this region, 5 countries were most often hit by natural disasters;

Table 1. Natural Disasters in MNA

\begin{tabular}{ccccc}
\hline & $\mathbf{2 0 1 5}$ & $\mathbf{2 0 1 4}$ & $\mathbf{2 0 1 3}$ & $\mathbf{1 9 0 0 - 2 0 1 5}$ \\
\hline $\begin{array}{c}\text { No. of countries affected from } \\
\text { disasters }\end{array}$ & 6 & 7 & 9 & 21 \\
\hline $\begin{array}{c}\text { No. of disasters } \\
\text { No. of deaths }\end{array}$ & 15 & 16 & 24 & 1070 \\
\hline No. of affected people & 1816 & 1128 & 1244 & 613634 \\
\hline Economic damages (US\$) & 1389959 & 3888094 & 2026895 & 212832485 \\
\hline & -- & 2413000 & 2200000 & 80090469 \\
\hline
\end{tabular}

Table 2. Human and Economic impact in MNA, 2014

\begin{tabular}{ccccc}
\hline & No. of Disasters & No. of Deaths & No. of People Affected & $\begin{array}{c}\text { Economic Damages (000 } \\
\text { US \$) }\end{array}$ \\
\hline Afghanistan & 3 & 575 & 150135 & 3000 \\
\hline $\begin{array}{c}\text { Pakistan } \\
\text { Morocco }\end{array}$ & 3 & 410 & 2530755 & 2018000 \\
Sudan & 3 & 60 & 117000 & 300000 \\
\hline Iran & 1 & 39 & 266204 & 0 \\
\hline Algeria & 3 & 38 & 452580 & 92000 \\
\hline Somalia & 1 & 6 & 420 & 0 \\
\hline Sum & 2 & 0 & 371000 & 2413000 \\
\hline
\end{tabular}




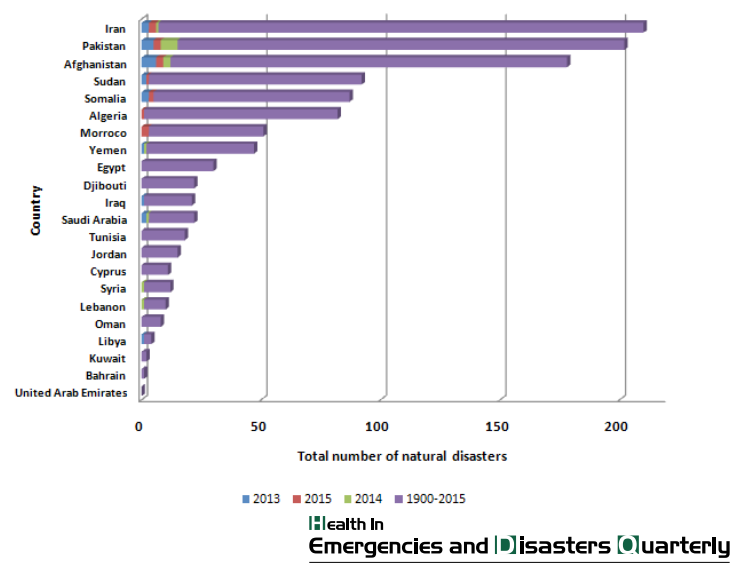

Figure 1. Events count in MNA in the last century and years

Afghanistan, Pakistan, Iran, and Morocco located in the 1st rank (with 3 disasters) in 2014. When considering the top 3 countries about the number of disasters, often Afghanistan, Pakistan, and Iran appear prominently in the list of countries experiencing the highest number of disasters in this region (Table 2).

In 2014, Pakistan was the most disaster-affected country, with flood, storm, and extreme temperature. Flood in Afghanistan and Pakistan killed more than 700 people and Afghanistan was the country with the highest mortality rate due to natural disasters in 2014 (Table 2).

From 1900 to 2015, about 1070 cases of natural disasters happened in 21 countries out of which 367 cases occurred in 18 countries in MNA over the last decade (Table 1). Afghanistan, Pakistan, Iran, Somalia, and Sudan constitute the top 5 countries that were most frequently hit by natural disasters (Table 2). The number of natural disasters reported in 2015 ( 15 cases) showed a decrease of $33 \%$ compared with that of 2013 (24 cases), and it was in the same range of the last decade.

In 2015, with 15 natural disasters reported, Afghanistan, Pakistan, and Iran experienced the highest number of natural disasters in MNA. The years 2015, and 2014 were notable years for Afghanistan and Pakistan with higher disaster occurrences compared with other countries in this region. In this period, 5 natural disasters reported with 52 death, 26430 victims, and US \$ 636 million damage in Iran. Iran with 208 natural disasters, 156332 deaths, 44643890 affected people, and US \$ 23492696 damage had the 1st rank from 1900 to 2015 in MNA. In Iran, the highest record for natural disasters was 9 cases that occurred in 1987, 2002, and 2005.

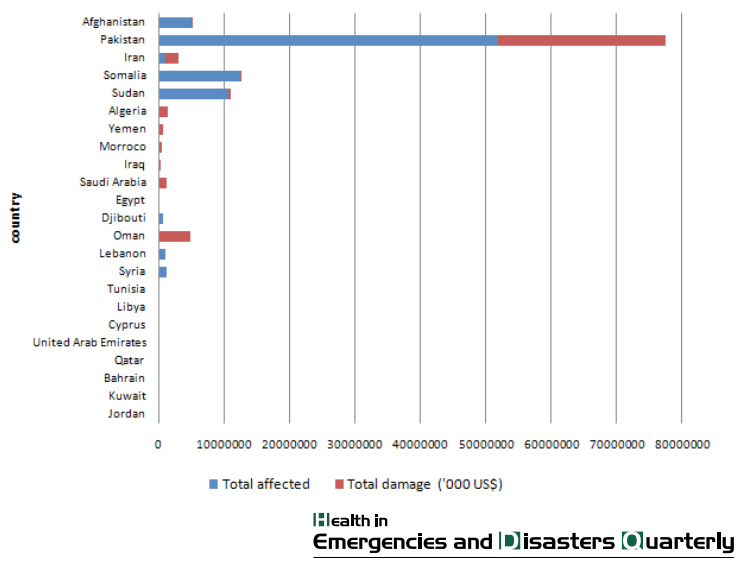

Figure 2. Human impact by natural disasters in MNA in the last decade

The highest total number of deaths by natural disasters showed in 1990 with about 40042, in 2003 with 26817, and in 1978 with 25053 cases that all of them were by earthquakes. The highest number recorded for people affected by natural disasters were related to floods and droughts in 1999 with 37028120 (by drought), in 2001 with 1206250 (by flood) and in flood with 800100 (by flood). Also in 1990, earthquake with US \$ 8309700, in 1992, flood with US \$ 3469400, and in 1999, drought with US \$ 3343000 had the highest damage level in Iran in this period. Totally, earthquakes with 106 cases and floods with 88 cases accounted for the highest number of natural disasters, total deaths, victims, and total damages in Iran in the last century. Although Iran was on the top in events count in the last century, in the last decade Afghanistan and Pakistan had higher statistics. In 2015, Afghanistan and Pakistan were in the list of top 10 most affected countries worldwide. In this period, Pakistan

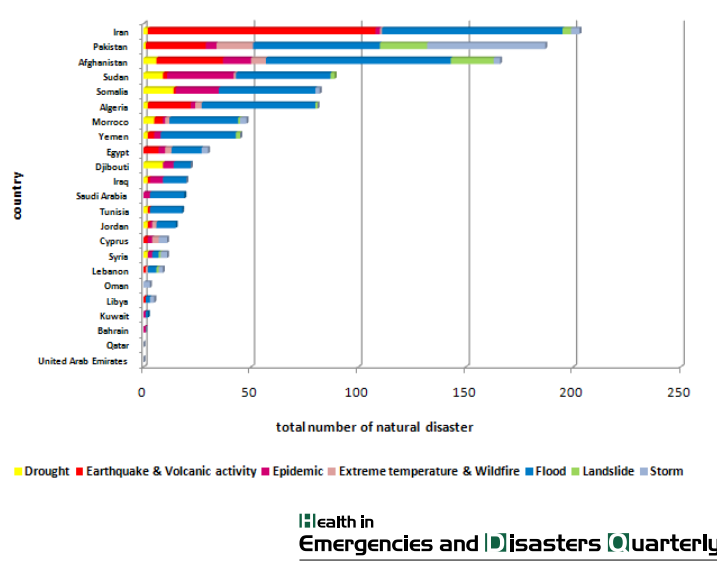

Figure 3. Occurrences of natural disasters by type in MNA (1900-2015) 


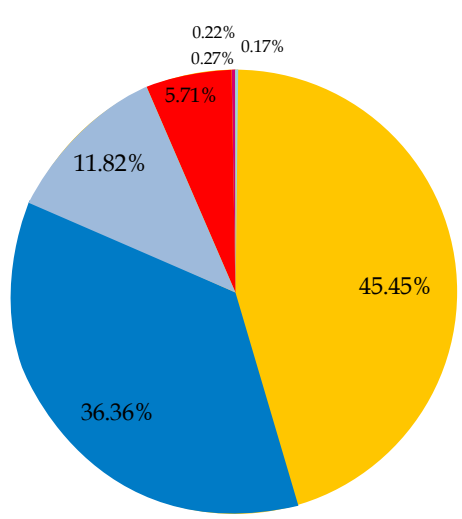

Total affected people

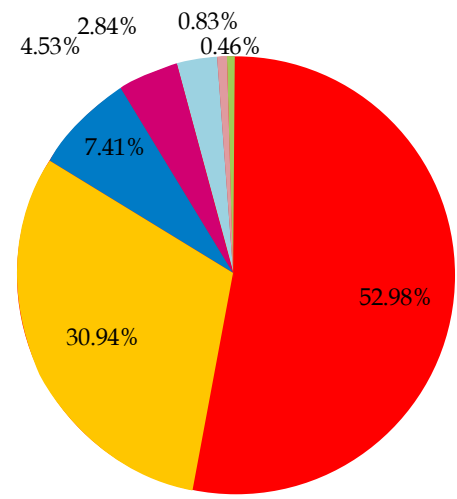

Total death

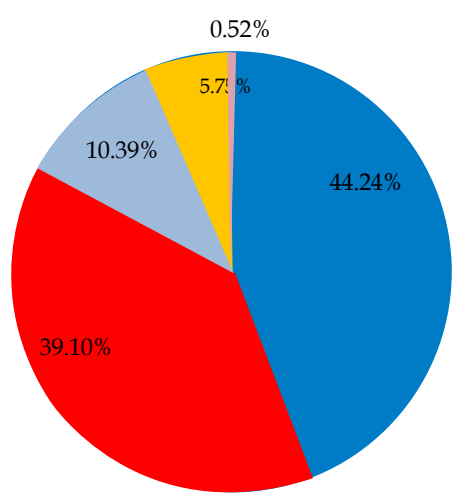

Total damages (US\$ '000)

- Geophysical(Earthquake \& Volcanic activity) Drought $\quad$ Flood

घpidemic Storm Extreme temperature \& wildfire Landslide

Figure 4. Human and Economic Impact of Natural Disasters by Type in MNA; 1900-2015

with 1867 deaths was the 4th and Afghanistan with 433 deaths was the $7^{\text {th }}$ among the studied countries.

In the last decade, from 367 cases of natural disasters reported in MNA, 82\% natural disasters happened in Afghanistan, Pakistan, Iran, Somalia, Sudan, Algeria, and Yemen. In this period, Afghanistan with 77 cases had the highest incidents and Cyprus and Libya with 1 case had the lowest incidents in this region. Besides, from 1900 to 2015, Qatar and United Arab Emirates no disaster was reported. Despite the fact that Iran was on the top in the last century among MNA members, in the past years (2013, 2014, and 2015) Afghanistan and Pakistan had the highest incidents in this region (Figure 1).

In the last 10 years, 114981 people lost their lives for natural disasters in MNA. Pakistan and Somalia had the highest mortality rate with 104009 (89\%) cases of the total number of death by natural disasters and Cyprus, with 4 cases that was due to an extreme temperature, had the lowest rate in this period. Only $1 \%$ of the total number of death by natural disasters was in Iran. The year 20151816 cases died for natural disasters was the lowest in the average of last decade and last century, but this rate compared with other countries, especially with that of high-income countries was notable (Figure 2).

From 1996 to 2015, low- and middle-income countries constituted more than $90 \%$ of disaster mortality; Pakistan and Iran, as low- and middle-income countries, were in the list of top 10 countries for disaster deaths. Due to incidence of earthquakes in the 2 highest middle-income countries, more than 100000 people passed away. In the top 10 countries for disaster deaths per 100000 inhabitants, from 1996 to 2015, there were 3 countries of MNA: Somalia, Pakistan and Pakistan. Somalia had the 3rd ranking in per 100000 populations, predominantly due to the 20000 lives lost to drought from 2006 to 2015 as well as high flood mortality during 1996 to 2005 .

In the last century, from 1900 to 2015, Pakistan with 176020 deaths and Iran with 156303 deaths had the 1st and 3rd ranking in MNA, respectively. In this period, natural disasters did not happen in Qatar and United Arab Emirates and no one died in these countries due to natural disasters. Kuwait with 2 deaths had the lowest number of death in this period.

In 2014, people often died for flood, storm, and extreme temperature and it was in the same range of the last decade. Also in 2015, extreme temperature was the most important cause of death due to natural disasters. Flood killed more than 700 people in 2014: in Afghanistan 512 deaths and in Pakistan 255 deaths. In terms of disaster mortality, Afghanistan, Pakistan, Iran, and Sudan were the countries with high mortality by natural disasters in 2014 and the last decade.

The number of people affected by natural disasters in the last decade was 85035427; Pakistan, Somalia, and Sudan with $61 \%, 14 \%$, and $12 \%$ had the highest levels of death, respectively in MNA, and Iran with 1\% (1064504 cases) was affected by natural disasters in this period. In this region, the lowest number of people affected by natural disaster was in Libya with 2000 cases caused by a flood in this period. 
In MNA, Total damage of natural disasters in the last decade was US \$ 36020317000 ; in this period, Pakistan with $70 \%$ (US \$ 25506118) was on the top and Oman with $13 \%$ was the next, this situation was due to 3 cases of storm in Oman. Iran with 5\% (US \$ 1928262000) economic losses was in the 3rd place that the biggest portion was due to 24 cases of earthquakes with US \$ 1265262000 economic losses. Whereas Somalia with US \$ 20000 had the lowest economic losses; Egypt, Djibouti, Tunisia, Jordan, Syria, Cyprus, Lebanon, Libya, Kuwait, Bahrain, Qatar and United Arab Emirates reported no loss in this period.

Regarding the total number of affected people, 3888094 cases in 2014 and 1389959 cases in 2014, the rate appears to be below its 1900 to 2015 average with 9253586 cases. This decrease is mainly explained by the lower human impact of climatological disasters. The number of reported victims in 2014 was almost twice the number of victims in 2013, but it was very far below the average of the last century. In 2015 this number was significantly lower than the number of victims reported in 2014. In the last century, from 1900 to 2015, Pakistan with 89736723, Iran with 44621490 and Sudan 38154918 people affected by natural disasters were the top 3 countries in MNA. Except Qatar, United Arab Emirates, and Bahrain with no affected people, and Kuwait with 201 had the lowest rate in MNA. In 2014, flood affected more than 2500000 people in Pakistan and in 2015, a storm in Lebanon had 1000000 severely affected victims. Also in the last decade and in the period of 1900 to 2015, flood had the highest impact with more than 57000000 affected people.

Economic losses from natural disasters in 2014 (US \$ 2413 billion) was $30 \%$ below its 1900 to 2015 average of US \$ 3482 billion. And it was higher than the damage average (US \$ 1566 billion) in the last decade. A flood in Pakistan had a total of US \$ 2 billion damage. Pakistan accounted for $83 \%$ of all reported damages, Algeria accounted for $12 \%$ of MNA disaster costs, Iran $4 \%$, and Afghanistan 1\%. However, Pakistan had a significant difference with other countries (Figure 2). When comparing gross domestic product (GDP) in these countries, in all of them, GDP was less than US \$ 400000 million. Among these countries in 2013, three had GDP per capita less than US \$2000 and 2 of them with GDP per capita more than US \$3000 and all of them were the lower-middle-income economies. Also, social expenditures (GDP\%) in 2013 were Iran 17.2\%, Afghanistan $5.45 \%$, and Pakistan $3.82 \%$ that were approximately less than those of high-middle-income countries.
The countries in this region were affected by a variety of disaster types, including 8 floods, 3 landslides, 3 earthquakes, 1 extreme temperature, and 1 epidemic in 2015. Hydrological disasters, especially floods, had the largest share in natural disaster occurrences in 2015 (53\%) in MNA. Floods caused $21 \%$ of total disaster victims, and were responsible for $11 \%$ of the total reported number of people killed in 2015. Mortality rate of flood with $(+11 \%)$ in 2015 and $(+75 \%)$ in 2014 was $7 \%$ higher than that of the portion in the last century (Figure 4$)$. The frequency of floods (53\%) was more than that of the last century (49\%). In the last 2 years, conversely, damages from flood were about $85 \%$, which was $44 \%$ (Figure 4 ). higher than that of the last century. In the period of 1996 to 2015, Afghanistan, Pakistan and Iran were the highest but Afghanistan and Somalia located in the list of top 10 countries for Mortality per 100000 inhabitants by flood (Figure 3). The important plans for reductions in flood deaths in the two decades was done in some countries such as Iran and Somalia. In Pakistan, more than 5100 people died in floods from 2006 to 2015, more than 2470 cases in 1996 to 2005, which placed Pakistan in 3rd place for flood mortality after India and China in the past decade. Landslides of hydrological disasters represented 20\% in 2015 and it had an increasing trend of $5 \%$, compared with the last century. Mortality rate by landslides $(32 \%)$ had an increasing trend, compared with the last century (about 1\%), and victims from this kind of disasters with $1 \%$ had the same portion.

In 2015, meteorological disasters (storms and extreme temperatures) represented $19 \%$ of the total disaster occurrences, which had an increasing trend, compared with the last century with $12 \%$ in MNA. Pakistan with $65 \%$ occurrences of storms and $40 \%$ occurrences of extreme temperatures had the notable differences with others in 1900-2015 (Figure 3). In 2015, Storms with $72 \%$ victims and extreme temperature with $57 \%$ mortality had the highest levels among other natural disasters in the period in MNA. Two storms and 1 extreme temperature were reported, in this time. A notable increase was shown in mortality portion of extreme temperatures in $2015(+57 \%)$ and in $2014(12 \%)$, compared to the last century (Figure 4). Also, share of mortality by storm was $11 \%$ in 2014 , whereas this portion in the last century was less in MNA (2.8\%) (Figure 4).

Also, damage caused by storm was about $12 \%$, which was above the centennial average (Figure 4). Although none of the countries in MNA was in the list of mortality per 100000 inhabitants for top 10 countries reporting storm deaths 1996 to 2015, considering the increasing trend of this type of natural disasters in MNA and also 
the experiences of other countries such as India to reduce storm deaths, improvement of the early warning systems, effective evacuation management and totally better preparedness is necessary in this region.

Although the frequency of climatological (drought) and geophysical disasters (earthquake) in 2014, 2015 and last century did not change, the number of people affected by drought with $9 \%$ in 2014 and $0 \%$ in 2015, and earthquake with less than $1 \%$ in 2014 and $0 \%$ in 2015 had a noticeable decrease, compared to the last century in MNA (Figure 4). One case of epidemic was reported in Yemen with 3 killed and 3026 victims, which was less than $1 \%$ among natural disasters in MNA. In this region, compared to the last century, a noticeable decrease of the portion of deaths and damage by drought and earthquake was observed. In 2014 and 2015, drought caused no death, and also, the rate of death by earthquakes was less than $1 \%$ in 2014. But in the period of 1996 to 2015 , four low- and middle-income countries, Afghanistan, Pakistan, Iran, and Algeria, were in the list of mortality per 100000 inhabitants for top 10 countries reporting earthquake deaths (Figure 3).

Among these countries, Iran had a huge reduction in earthquake mortality, down from 30500 in 1996 to 2005 to 438 in the following decade. In the case of Iran, this can be partly attributed to a massive investment program, particularly in safe schools; therefore, a low national mortality rate is no reason for complacency and every country, especially low- and middle-income countries, in a seismic zone needs to invest in building codes and ensure compliance with them. It is critically important to focus on earthquake-resistant housing, schools, health care facilities, and work places.

\section{Discussion}

Trend of natural disasters losses the reveal need to focus on a suitable preparedness, response, and recovery that varies based on the type of disaster and its magnitude, the geography of the affected area, the dynamics of the impacted population, and the situation of the individual victim $[10,11,12]$. While the number of natural disasters around the world has almost doubled since the 1980s, the average number of natural disasters in Asia has almost tripled over the same period. In Asia, the synergy of natural disasters, rapid urbanization, water scarcity, and climate change emerged as a serious challenge for policy and planning [13]. The growing urbanized population and climate changes in this continent result in disasters affecting more people and causing more damage in future [14, 15].
MNA's rapid urbanization is increasing the exposure of people and economic assets to disasters. The urban population already accounts for $62 \%$ of the total population and is expected to double in the next decades [16]. Citizens in urban areas should deal with floods on a regular basis, with limited structural protection, inadequate citywide drainage systems, and weak nonstructural flood mitigation measures. The impact of urbanization is especially important in the region's coastal areas, where the largest cities and economies are located. Today, approximately 60 million people (about $17 \%$ of MNA's total population) live in the coastal areas of the region. Rapid growth of informal settlements is resulting in greater exposure to floods. If urban development continues irregularly, it will lead to the creation of new disaster risks [13, 17]. The future of the roughly 100 million poor people who are the least resilient to disasters is the most concerning issue. According to the inter-governmental panel on climate change, sea-level rise would cause millions to be displaced in the region [18].

With regard to the different levels of development in MNA, during 1900 to 2015 , more than $80 \%$ of the natural disaster events in MNA were concentrated in just 9 countries: Afghanistan, Pakistan, Iran, Sudan, Somalia, Algeria, Morocco, Yemen, and Egypt. In this period, 1070 natural disasters were recorded, about 212 million people were affected, and about 614000 people died for natural disasters [19]. Compared to the last century, a noticeable decrease of the number of death due to natural disaster was observed in 2015. Although global flood mortality risk has decreased since 2000, in MNA and some other regions, this type of disaster is still increasing and with $49 \%$ frequency was the 1st disaster with serious economic impacts (44\%) in this region in the last century. The percentage of GDP exposed to floods, the most recurrent hazard in the region, has tripled from 1970 s to 2000 s $[9,19,20]$. Also, Mendelsohn predicated an increasing frequency, severity, and damage of flood and tropical cyclone in future in the East Asia region, even without climate change [15].

Mirza indicated that flooding was identified as one of the major destructive disasters in South Asia and already caused enormous damage to lives and properties. Flooding has also an increasing trend in Bangladesh, India, and Pakistan, and is responsible for very high human and economic losses. Also, he explained that precipitation is the major cause of flooding in all the countries in South Asia that are more vulnerable to flooding [22].

Earthquakes with about $20 \%$ were the 2 nd most prevalent disasters in the region in the last century with the high- 
est mortality (53\%). Droughts recurrently hit the region, bringing significant water shortages, economic losses, and adverse social consequences. Affected people by drought with the rate of $45 \%$ was the highest percentage among natural disasters in this region in the last decade [9, 20,21].

A study on landslide trend showed an increasing trend, but there are not sufficient data to confirm it. The current study also explained that the highest number of fatalities occurred during the monsoon season in most of the South Asian countries. The increase in the death rate could be due to an increase in the population who knowingly or unknowingly continue to reside in the vulnerable areas [23], but the percentage of landslide during the last decade shows a decrease trend compared to the last century in MNA.

Year after year, the share of each type of disasters remains more or less similar and relatively stable. Inversely, the notable differences in indicators such as: people killed, numbers of victims, and amounts of damage from 1 year to another indicate high variability and diversity of the impacts of disasters over time. Valuable information and trends of natural disasters and their impacts on human and society is necessary to codify and develop plans, guidelines, and tools in the level of international, national, and sub-national for disaster risk reduction $[8,9]$.

Governments should increasingly seek comprehensive disaster risk management services. These programs include early warning systems and national and city-level risk assessments. Therefore, some programs are designed for disaster reduction and recovery in some countries in MNA since 2007, such as Djibouti, Morocco, Algeria, and Yemen to increase their disaster resilience. These programs include activities aimed at improving access to information on disaster risks, developing plans and policies for risk reduction, building capacities, and empowerment through training at the national and local levels, and creating state-led, post-disaster recovery and reconstruction programs [13].

Also, World Bank priorities for action in the region are organized around 5 items: 1) Institutional capacity building, education, and knowledge sharing; 2) Risk identification; 3) Risk reduction; 4) Risk financing and transfer; and 5) Response, recovery, and reconstruction [13]. But, despite all activities, the current disaster management act seems to be weak and traditional and misses out the provision of proactive mitigation measures such as preparedness and mainstreaming of hazard reduction in the development process, and the existing legal documents focus more on response than preparedness, especially in low- and middle-income countries. Therefore, for these countries disaster preparedness should be considered as a better option than response and a well-executed plan with more practice on intensive risk scenarios is so helpful [24]. Hence, it can be more effective to establish a national office for disaster risk reduction for better planning and operation in every country, especially in lowand middle-income ones. Coordination and strengthened collaboration between stakeholders working in the emergency response is a basic factor in disaster management

Another point that is necessary in disaster management is the need for reliable and timely hazard warnings, which are crucial to ensure that the health system is ready for effective service delivery during emergencies and could help to protect vulnerable populations. Strengthened social safety networks, public awareness, and training should be included as part of a cost-effective approach to build a culture of prevention in the community, too. Structural and non-structural safety and existence of stiff rules in the building code and of planning for responses and drills should not be missed in disasters risk reduction management. Importance of access to databases, such as those containing spatial and geographic information, and communication and information exchange among organizations, and also access to sufficient financial resources for disaster risk reduction and strengthened credible insurance mechanism are important points in effective response in this region $[13,25]$.

\section{Conclusion}

Disasters that are unexpected and occur suddenly cause widespread damage, loss, destruction, and devastation to life and property. The severity of the human and economic impacts of natural disasters is directly related to the type and severity of disaster and also income and development level in countries. Therefore, with regard to the increasing trend of damages, losses, and mortality by hydrological disasters, especially floods, and geophysical disasters, especially earthquake and drought, in the last century and also the existence of low- and middleincome countries in MNA, understanding of risk, planning for disaster risk reduction, and coordination are necessary for all countries in this region.

With regard to direct association between urbanization and climate changes with weather- and climate-related hazards in low- and middle-income countries, there is a need to promote the mainstreaming of disaster risk assessments into land-use policy development and implementation, including urban planning, building codes, and investing in infrastructure safety, notably housing, schools, health care facilities, and work places, and plans related to environ- 
ment. Establishing a national on-line data bank to collect and analyze the data and develop strategic managing plans is an important factor in disaster risk management.

It is helpful to promote the cooperation of diverse institutions, authorities, and related stakeholders at all public and private levels; and invest more to make communities prepared for disasters and less vulnerable by establishing community centers to promote public awareness; provide continuous training programs for students in schools and universities as well as the general population. It is clear that priority and implementation of these actions and achievement of the goal of disaster risk reduction would verify only with the effective mitigation and preparedness plans, both at individual and governance levels. This issue in the low- and middle-income, and developing countries in MNA should be considered more and have a high priority in national planning.

\section{Acknowledgements}

This research did not receive any specific grant from funding agencies in the public, commercial, or not-forprofit sectors.

\section{Conflict of Interest}

The authors declared no conflict of interests.

\section{References}

[1] Guha-Sapir D, Hoyois Ph, Below R. Annual disaster statistical review 2015: The numbers and trends. Brussels: Centre for Research on the Epidemiology of Disasters; 2016.

[2] Gosney J, Reinhardt J, Haig A, Li J. Developing post-disaster physical rehabilitation: Role of the World Health Organization Liaison Sub-Committee on rehabilitation disaster relief of the International Society of Physical and Rehabilitation Medicine. Journal of Rehabilitation Medicine. 2011; 43(11):965-968 doi: 10.2340/16501977-0890

[3] United Nations. United Nations international strategy for disaster reduction, Natural disasters and sustainable development: Understanding the links between development, environment and natural disasters. Background Paper No. 5. Geneva: United Nations Department of Economic and Social Affairs; 2001.

[4] Reinhardt J, Li J, Gosney J, Rathore F, Haig A, Marx M, et al. Disability and health-related rehabilitation in international disaster relief. Global Health Action. 2011; 4(1):7191-9. doi: 10.3402/gha.v4i0.7191
[5] Center for Research on the Epidemiology of Disasters. Poverty \& death: Disaster mortality 1996-2015. Geneva: United Nations.

[6] Landry M, McGlynn E. Humanitarian response following the earthquake in Haiti: Reflections on unprecedented need for rehabilitation. World Health \& Population. 2010; 12(1):18 22

[7] Below, R. Vanderveken, A. Disaster data: A balanced perspective. No. 41. Geneva: United Nations, Center for Research on the Epidemiology of Disasters; 2016.

[8] Guha-Sapir D, Hoyois P, Below R. Annual Disaster Statistical Review 2014 - The numbers and trends. Brussels, Belgium: Centre for Research on the Epidemiology of Disasters; 2015.

[9] Centre for Research on the Epidemiology of Disasters. Emergency Events Database (EM-DAT). The International Disaster Database [Internet]. 2015 [Cited 2015 February 2]. Available from: http://www.emdat.be

[10] Bai XD, Liu XH, Retrospective analysis: The earthquakeinjured patients in Barakott of Pakistan. Chinese Journal of Traumatology. 2009; 12(2):122-124. doi: 10.3760/cma.j.is sn.1008-1275.2009.02.012

[11] Iezzoni LI. Disability legacy of the Haitian earthquake. Annals of Internal Medicine. 2010; 152(12):812-9. doi 10.7326/0003-4819-152-12-201006150-00234

[12] Phalkey R, Reinhardt J, Marx M. Injury epidemiology after the 2001 Gujarat earthquake in India: A retrospective analysis of injuries treated at a rural hospital in the Kutch district immediately after the disaster. Global Health Action. 2011; 4(1):7196. doi: 10.3402/gha.v4i0.7196

[13] United Nations. Natural disasters in the Middle East and North Africa report: A regional overview. Geneva: United Nations; 2014

[14] Turner AG, Annamalai H. Climate change and the South Asian summer monsoon. Nature Climate Change. 2012; 2(8):587-95. doi: 10.1038/nclimate1495

[15] Mendelsohn R, Emanuel K, Chonabayashi S, Bakkensen L. The impact of climate change on global tropical cyclone damage. Nature Climate Change. 2012; 2(3):205-9. doi: 10.1038/ nclimate1357

[16] UN-Habitat. The State of Arab Cities 2012: Challenges of Urban Transition. Geneva: UN-Habitat; 2012

[17] World Bank. World development indicators [Internet]. 2017 [Updated 2017 February 01]. Available from: http:// data.worldbank.org/data-catalog/world-development-indicators

[18] Open Knowledge Repository. Adaptation to a changing climate in the Arab countries: A case for adaptation governance and leadership in building climate resilience. Washington: World Bank; 2012

[19] United Nations. Global assessment report on disaster risk reduction. New York: United Nations; 2011

[20] United Nations. The Global Assessment Report on disaster risk reduction (GAR) 2015. New York: United Nations; 2015.

[21] Kouadio IK, Aljunid S, Kamigaki T, Hammad K, Oshitani $\mathrm{H}$. Infectious diseases following natural disasters: Prevention 
and control measures. Expert Review of Anti-infective Therapy. 2012; 10(1):95-104. doi: 10.1586/eri.11.155

[22] Mirza MMQ. Climate change, flooding in South Asia and implications. Regional Environmental Change. 2010; 11(1):95-107. doi: 10.1007/s10113-010-0184-7

[23] Bozkurt M, Duran S. Effects of natural disaster trends: A case study for expanding the pre-positioning network of care international. International Journal of Environmental Research and Public Health. 2012; 9(12):2863-74. doi: 10.3390/ ijerph 9082863

[24] Petley DN, Hearn GJ, Hart A, Rosser NJ, Dunning SA, Oven K, et al. Trends in landslide occurrence in Nepal. Natural Hazards. 2007; 43(1):23-44. doi: 10.1007/s11069-006-9100-3

[25] Farthing DW, Ware M. When it comes to mapping developing countries, disaster preparedness is better than disaster response. Paper presented at: AGI GeoCommunity 10: Opportunities in a Changing World Innovate - Connect - Succeed, 2010 September 28-30; Stanford, USA. 